
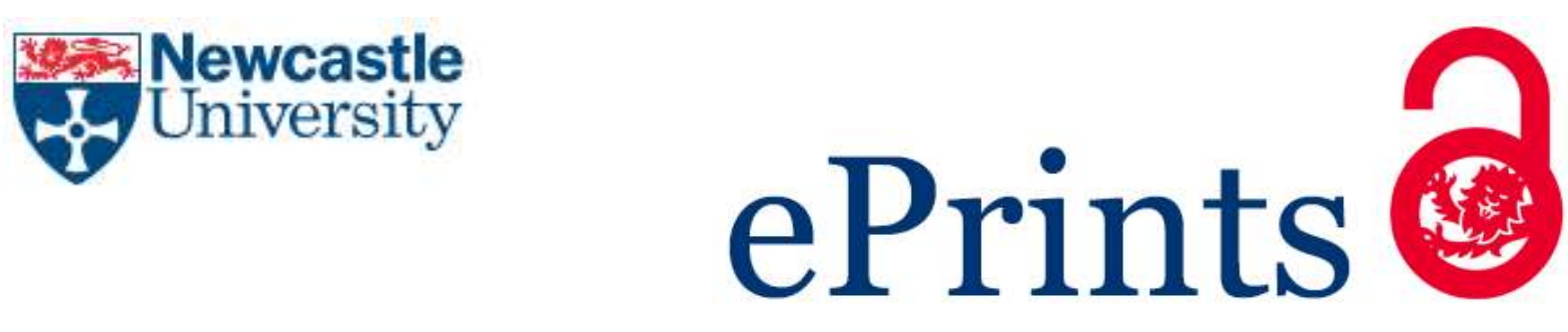

Blaylock P, Ellis JS, McCracken GI.

The transition from dental school to postgraduate dental foundation training: strengthening the interaction between stakeholders.

British Dental Journal 2018, 224(4), 269-273.

\title{
Copyright:
}

This is the authors' accepted manuscript of an article that has been published in its final definitive form by Nature Publishing Group, 2018.

DOI link to article:

https://doi.org/10.1038/sj.bdj.2018.79

Date deposited:

$08 / 05 / 2018$

Embargo release date:

16 August 2018 


\section{The transition from Dental School to postgraduate Dental Foundation Training: strengthening the interaction between stakeholders}

An education commentary submitted to the British Dental Journal

Mr P Blaylock ${ }^{1}$

Professor JS Ellis ${ }^{2}$

Dr GI McCracken²

${ }^{1}$ Health Education England, working across north east and north Cumbria

${ }^{2}$ University of Newcastle upon Tyne School of Dental Sciences

Address for correspondence

Professor JS EllisMr P Blaylock

Newcastle University School of Dental Sciences Health Education England, working across

north east and north Cumbria

Framlington PlaceBourne House

Mandale Business Park

Neastle un Tymam

NE24BWDH1 1TH

UK

janice.ellis@neweastle.ac.ukpaul.blaylock@hee.nhs.uk

Formatted: Default Paragraph Font 


\section{Abstract}

This opinion piece demonstrates the benefits of collaboration between dental educators in undergraduate and postgraduate settings, to facilitate the transition of dental students into Dental Foundation Training (DFT). The School of Dental Sciences at Newcastle University and Health Education England, working across north east and north Cumbria, have strengthened links by forming a Dental Foundation Programme Undergraduate Liaison Group (FPUG) involving all stakeholders. The group has shared information between the organisations, enhanced stakeholder engagement, and developed several initiatives including workshops to help prepare final year students for the transition to DFT. _A small investment in time has been highly effective, and the formation of a similar group merits consideration in other areas of the UK. 


\section{Introduction}

Most UK dental and medical undergraduates progress into NHS posts involving further postgraduate training. Two key organisations, a higher education institution (University) and Health Education England (Postgraduate Dental Deanery), interface at this transition. It has been suggested that collaboration between these two organisations at this key transition is imperative to facilitate tailored training supporting personal, professional and clinical development. ${ }^{1}$ This collaboration is now well established in Dentistry at Newcastle University and Health Education England, working across north east and north Cumbria (HEE $\mathrm{NE}$ ) under the umbrella of a Dental Foundation Programme Undergraduate Liaison Group (FPUG).

This opinion piece provides the historical context of the relationship between these two key stakeholders in dental education and the establishment of the current positive and productive collaboration. We wish to pass on what we have learned and encourage others in similar roles to initiate and establish this type of group to support learners at a fundamental transition in their clinical and professional development.

\section{Historical context of group}

Prior to the establishment of FPUG, the School of Dental Sciences and what was then the Postgraduate Dental Deanery strove to establish a forum for communication across this interface. This took the format of a large-scale lecture theatre based meeting. All Vocational Training Trainers in the region were invited along with those members of clinical staff from the School and Hospital that were appointed as Educational Supervisors to trainees undertaking the two year longitudinal training programme (General Professional Training).

It is unclear whether formal terms of reference were ever established for this group, as no minutes were recorded. Anecdotally, the meeting became an opportunity for both parties to vocalise criticisms of one another, with discussions often straying beyond the intended context and spirit of the meeting. These interactions were seldom helpful to either party and on occasion generated animosity.

As a consequence, and despite the meetings being held within working hours, many of the Ttrainers and Educational Ssupervisors- distanced themselves from attending $\mathrm{L}_{\mathrm{L}}-\mathrm{p}$ Perhaps demonstrating a lack of interest and further deterioration of the intended relationship. The meetings were perceived to be damaging unhelpful to allboth parties and abandoned.

In September 2009 the initiative was taken to re-establish a forum using a smaller group of leaders of dental education from the Dental Deanery and University. The agenda of the initial meeting was to discuss the concept of ${ }_{2}$ and define clear terms of reference for ${ }_{2}$ membership of this re-established group. Subsequent to this, the purpose, terms of reference and membership has been iteratively redefined to take into consideration changes to the organisational structures of postgraduate clinical education. 


\section{Current Position}

Specifically the responsibilities of the group as described in its Terms of Reference, are to:

- Play an active role in stakeholder engagement ${ }_{i}$

- Work collaboratively in the development and delivery of initiatives;

- Demonstrate the values and behaviours of the NHS constitution as it conducts its business;

- Maintain clear lines of communication between the two organisations;

- Advise the Postgraduate Dental Dean on matters relating to the Dental Foundation Training (DFT) undergraduate interface;

- Provide a unique forum for senior members of the staff of the School of Dental Science, DFT Programme Directors, DFT Educational Supervisor (ES) representative, Trainee representatives and undergraduate representative to share ideas and best practice, and develop proposals for new ways of working and innovation:

- Provide a means of communicating local and national information, procedures and policies relating to Dental Foundation Training.

The membership of the group is shown in Table 1.

\section{Table 1 - membership of FPUG}

Formatted: Heading 2

Directorate of Multi-Disciplinary Dental Education, HEE NE

- Postgraduate Dental Dean (Joint Chair)

- Regional Dental Foundation Programmes Advisor

- Dental Foundation Training Programme Directors

- DFT Foundation Dentist Reps Forum Representative

- DFT Educational Supervisors Representative

- In attendance: Dental Foundation Coordinator (Secretary)
School of Dental Sciences

- Stage 5 (Final Year) Director (Joint Chair)

- Director of Clinical Studies

- Director of Student Progression

- Degree Programme Director

- Stage 5 Student Representative/s

- Stage 5 Personal \& Professional Development Course Leader

$\underline{-}$
Formatted: Bulleted + Level: $1+$ Aligned at: $0.63 \mathrm{~cm}+$ Tab after: $1.27 \mathrm{~cm}+$ Indent at: $1.27 \mathrm{~cm}$

The group normally meets twice a year with hosting alternating- between the School and HEE NE. The Chair of the Group alternates between the Postgraduate Dental Dean and the BDS Stage 5 Director depending upon host venue. 


\section{Current key activities}

\section{Information sharing}

Significant value has been derived from two-way sharing of information and concerns between the School and HEE NE. Changes in DFT National Recruitment, $\underline{\underline{2}}$ Satisfactory Completion of $\mathrm{DFT}^{-}$and Dental Core Training ${ }^{4}$ have been shared with the School by HEE NE, allowing the students to be better prepared for their future career pathways. The results of the 2016 HEE NE Dental Workforce Survey ${ }^{25}$ stimulated discussion regarding the implications for undergraduate and postgraduate dental training, and workforce development, in the area.

The School has presented helpful information regarding the changing nature of dental student skills (both clinical and non-clinical) and experience upon graduation. This has enhanced the understanding of HEE NE and ESs in practice regarding the skill set of the 'safe beginner' when they commence DFT. .6 . Both parties have gained an increased awareness of dental educational research which is relevant to the transition to DFT, enhanced through FPUG discussions covering research related to ES expectations of dental graduates-discussed the implications of research relating to ES expectations of graduates. ${ }^{1}$

Soon after FPUG was formed, arrangements were made for HEE NE to communicate directly with students through Blackboard, the School's online learning environment. However, this was found not to be effective, and alternative communication pathways were enabled via FPUG members and events organised for the students.

\section{Stakeholder engagement}

A number of the activities of FPUG have resulted in the two organisations developing a better understanding of each other by engagement in each other's activities. For example;

- Academic members of FPUG are now involved as external panel members during HEE NE's EducationaLSupervisor recruitment for training practices, whilst the Postgraduate Dental Dean now attends the School's Executive meetings.

- Where appropriate, practice ESs +have been invited to attend the School's Educational Development Day, and Dental School/Hospital Educational Supervisors and final year Tutors have visited training practices to better understand the Foundation Dentist training environment.

Attempts to encourage engagement have met with varying success. Ppractice ESs were invited to visit and observe student clinics ${ }_{2}$ to promote opportunities to-and consider becomeing Associate Clinical Lecturers at the School and teach on student clinics. This approach was not successful, largely due to the issues surrounding obtaining observer status, howeveralthough a similar strategythis could be considered again. 
Initiative development and impact

FPUG discussions have resulted in a variety of new initiatives which we feel have benefitted all stakeholders, principally in relation to DFT National Recruitment, information sharing with the wider groups represented at FPUG, and changes to clinical training. A number of examples of the impact of these initiatives are highlighted here.

With the advent of DFT National Recruitment, the School was anxious to assist students in their preparation, without excessively coaching. $\underline{?}$ An annual Pprofessional Development Dday was developed with input from HEE NE, who delivered a lecture to final year students about the National Recruitment process, whilst ES's who were not scheduled to participate in National Recruitment but who had a clear understanding of the process assisted in delivering 'mock assessment-' opportunities for final year students. HEE NE arranged a highly popular final year student trip-visit to their dedicated Postgraduate training facility; this was promoted and advertised by the School staff and facilitated the students gaining a greater understanding and appreciation of the local DFT Schemes.

Both organisations wished to support students who failed to transition at the expected time $_{2}$ (through failure to obtain a DFT place nathen National Recruitment, or deferral or fresitting their fFinal BDS examinations). HEE NE provided timely support and reassurance and facilitated a programme of hands on clinical sessions at their training facility. These sessions aimed at preventingto prevent deskilling prior to applying again to National Recruitment. FPUG also considered how the organisations could work together to support remediation of Foundation Dentists with performance concernsin difficulty. $\underline{8}$ considered included direct input from the School, but it was agreed that HEE NE was best placed to support such dentists, through a process which has since informed national Satisfactory Completion protocols. ${ }^{-}$

The School took part in 'ES training' and provided average-summary data on the clinical experience data from their undergraduate portfolio - iDentity. ${ }^{-}$- This helped to manage ES expectations with respect to the typical volume and range of tis potentially inadequate undergraduate clinical experience, addressing a recognised source of tension between those involved with undergraduate and postgraduate dental education which has caused some to question the competence and preparedness of new graduates.., 10 Graduating students are also encouraged to share their personal clinical experience records from iDentity with their ES. ${ }^{1}$ Immediately prior to completion of the undergraduate programme the $\underline{S}$ school now supports final year students to extend their on-going Personal Development Plan into their DFT year, to share relevant information with their ES and incorporate it into their DFT e-Portfolio.

More recently at the behest of Foundation Dentist and student representatives on FPUG, HEE NE has produced a checklist of requirements post--graduation and before starting DFT, including items such as when to apply for Performer List entry. Also at the request of the Foundation Dentists, the Sschool has generated a list of specialist contacts from the School and Hospital, with whom Foundation Dentists could make contact to discuss their individual career plans. HEE NE has made this list available to all Foundation Dentists in their schemes. 
CSome changes to clinical training have arisen through FPUG discussions, in particular the introduction of clinical refresher sessions for new graduates over summer to address the risk of deskilling before commencing DFT in September. These have been delivered by both HEE NE Training Programme Directors and School staff, including the authors.

FPUG identified that further minor oral surgery training was a common learning need for new graduates, a widely acknowledged finding. 1,10,11 11 Staff within the School staff-became involved with delivering hands on study days in DFT to address this need.; Aas a result of which further significant development which arose was the piloting of a Level 2 training programme in oral surgery for local general dental practitioners has now been piloted.

The School recently established a Dental Educational Research Group ${ }_{\longleftarrow}^{12}$ and through FPUG several members of HEE NE have become involved with this group , and commenced collaborative research.

\section{Discussion}

The work of FPUG has been instrumental in fostering ever increasing collaboration between the School and HEE NE._All stakeholders value the close relationship between the organisations which has developed through meeting regularly, sharing information, and working together-. Initiatives which have originated in FPUG have been very-effective in helping to facilitate the transition from dental student to Foundation Dentist. Notable examples include the annual Pprofessional $\underline{D}$ development $\underline{D}$ day to help prepare final year students for DFT National Recruitment, and the student trip to the HEE NE facilities at Bourne House.

It is acknowledged that the geography in the North East of England is conducive to this close collaboration between the undergraduate School and DFT O, with over 85\% of Foundation Dentists in the HEE NE area having have graduated from Newcastle University historically, ${ }^{1}$ and an ongoing high proportion still having done so despite National Recruitment. _The benefit of a local group such as FPUG we feel could still be applied in many other parts of the UK, working with multiple universities and HEE local teams if necessary in some regions.

There are-have been a few areas where FPUG has not achieved the planned outcome, such as the failurenot being able to communicate directly between HEE NE and the undergraduate students using Blackboard. However, on reflection this route was perhaps not necessary and we have found alternative ways to communicate more effectively at all levels of both organisations. The unsuccessful plan to encourage more ESs to become Associate Clinical Lecturers in the School was not successful at the first attempt, but we feel this would be worthy of further consideration to strengthen direct links between undergraduate teaching and DFT.

Changes in DFT continue apace, $\underline{2,3}$ providing plenty of material for discussion in future FPUG meetings, and in turn generating innovative ways in which the organisations can mutually develop. We recognise the need to review the results of recent collaborative research undertaken locally and nationally on the transition to DFT. ${ }^{37,10,11}$ This analysis will hopefully 
generate proposals from FPUG for further local developments in relation to the undergraduate programme or DFT to better facilitate the transition.

\section{Conclusion}

By establishing and maintaining this FPUG group, and-with a small investment in time, all stakeholders involved with undergraduate and postgraduate dental training have benefited from the positive collaboration. The group has been highly effective at helping to facilitate dental students' transition into DFT in the North East of England and North Cumbria. Formation of a similar group merits consideration in other areas of the UK.

\section{Acknowledgements}

Formatted: Heading 1

In addition, the authors wish to thank Mr Malcolm Smith, Postgraduate Dental Dean and Mr John Ashman, Regional Dental Foundation Programmes at Health Education England working across the North East for their support and input in both FPUG and in preparation of this manuscript, without which this work would not have been possible. 


\section{References}

1. Gilmour A, Jones R, Bullock A. Dental foundation trainers' expectations of a dental graduate: final report. Cardiff: Cardiff University, 2012. Online information available at Available online at

Trainers-expections-of-new-graduates.pdf (accessed Julyne 2017).

2. UK Committee of Postgraduate Dental Deans and Directors. Dental foundation training (DFT) 2018 national recruitment. 2017. Online information available at http://www.copdend.org/content.aspx?Group=foundation\&Page=copy of foundation_dftnationalrecruitment 2018 (accessed July 2017).

3. UK Committee of Postgraduate Dental Deans and Directors. A reference guide for dental foundation training in England, Wales and Northern Ireland: The dental blue guide. 2016. Online information available at http://www.copdend.org//data/files/Foundation/Blue\%20Guide\%202016.pdf (accessed July 2017).

1.4. UK Committee of Postgraduate Dental Deans and Directors. Dental core training 2017 recruitment. 2017. Online information available at http://www.copdend.org/content.aspx?Group=foundation\&Page=2017 recruitment (accessed July 2017).

5. Vance G, Holmes R, Burford B, Shapiro E. Planning and developing the dental workforce of the future: a survey of the dental workforce in North East England and North Cumbria. Newcastle: Newcastle University, 2016. Online information available at Available online at https://madeinheene.hee.nhs.uk/Portals/13/Dental\%20Workforce\%20Survey\%20fin al.pdf (accessed Julyne 2017).

2.6. Ali K, Tredwin C, Kay E J, Slade A, Pooler J. Preparedness of dental graduates for foundation training: a qualitative study. Br Dent J 2014; 217: 145-149.

7. Ali K, Tredwin C, Kay E, Slade A. Transition of new dental graduates into practice: a qualitative study. Eur J Dent Educ 2016; 20: 65-72.

8. Japp E. Managing performance concerns in dental foundation training: a practical guide for trainers and educational supervisors. Cambridge: Health Education England, working across the East of England, 2016. Online information available at https://heeoe.hee.nhs.uk/sites/default/files/docustore/managing performance con cerns.pdf (accessed July 2017).

9. Newcastle University School of Medical Sciences Education Development. iDentity. 2014. Online information available at https://Itms.ncl.ac.uk/public/services/identity/ (accessed July 2017).

10. Oxley C J, Dennick R, Batchelor P. The standard of newly qualified dental graduates foundation trainer perceptions. Br Dent J 2017; 222: 391-395.

11. Oliver G R, Lynch C D, Chadwick B L, Santini A, Wilson N H F. What I wish I'd learned at dental school. Br Dent J 2016; 221: 187-194.

12. Newcastle University School of Dental Sciences. Research. 2017. Online information available at http://www.ncl.ac.uk/dental/research/ (accessed July 2017). 